\title{
Toxicokinetics of a urinary metabolite of tebuconazole following controlled oral and dermal administration in human volunteers
}

\author{
A. Oerlemans ${ }^{1}(1) \cdot$ L. F. M. Verscheijden ${ }^{2} \cdot$ J. G. J. Mol ${ }^{3} \cdot$ R. C. H. Vermeulen ${ }^{4} \cdot$ J. Westerhout $^{5} \cdot$ N. Roeleveld $^{1}$. \\ F. G. M. Russel ${ }^{2} \cdot$ P. T. J. Scheepers ${ }^{1}$
}

Received: 12 April 2019 / Accepted: 18 July 2019 / Published online: 29 July 2019

(c) The Author(s) 2019

\begin{abstract}
Tebuconazole (TEB) is a widely used triazole fungicide, but the toxicokinetics of its human metabolites are not fully described. For proper interpretation of biological monitoring data, knowledge on the metabolism and elimination of the compound is required. A human volunteer study was performed with the aim to describe the time courses of urinary excretion after controlled oral and dermal administration of TEB. Six healthy volunteers (three males and three females) received on separate occasions a single oral dose of $1.5 \mathrm{mg}$ of TEB and a single dermal dose of $2.5 \mathrm{mg}$ during $1 \mathrm{~h}$. In addition to a pre-exposure urine sample, complete urine voids were collected over $48 \mathrm{~h}$ post-administration. The main metabolite hydroxytebuconazole (TEB-OH) was quantified in each urine sample. Peak excretion rates after oral and dermal administration were reached after 1.4 and $21 \mathrm{~h}$, mean elimination half-lives were 7.8 and $16 \mathrm{~h}$, and recoveries within $48 \mathrm{~h}$ were $38 \%$ and $1 \%$, respectively. The time courses of excretion were compared to simulations with an established physiologically based toxicokinetic model for TEB that was extended with a parallel model for TEB-OH. Overall, TEB-OH was rapidly excreted into urine after oral exposure, and renal elimination was considerably slower after dermal exposure. Urinary time courses between individuals were similar. The model predictions were in good agreement with the observed time courses of excretion.
\end{abstract}

Keywords Human volunteer study $\cdot$ Tebuconazole $\cdot$ Urine $\cdot$ Biomarker $\cdot$ Toxicokinetics $\cdot$ PBTK

\section{Introduction}

F. G. M. Russel and P. T. J. Scheepers both authors contributed equally.

Electronic supplementary material The online version of this article (https://doi.org/10.1007/s00204-019-02523-5) contains supplementary material, which is available to authorized users.

A. Oerlemans

arne.oerlemans@radboudumc.nl

1 Radboud Institute for Health Sciences, Radboud University Medical Center, P.O. Box. 9101, 6500 HB Nijmegen, The Netherlands

2 Radboud Institute for Molecular Life Sciences, Radboud University Medical Center, Nijmegen, The Netherlands

3 Wageningen Food Safety Research, Wageningen University and Research, Wageningen, The Netherlands

4 Institute for Risk Assessment Sciences, University Utrecht, Utrecht, The Netherlands

5 TNO, Zeist, The Netherlands
Tebuconazole (TEB) is a widely applied triazole fungicide used against mildew, brown rot blossom, twig blight, dry rot, leaf spots, and as a growth regulator (Bowen et al. 1997; Child et al. 1993; Larena et al. 2005; Mohapatra et al. 2010; Rademacher 2000; Zhang et al. 2010). TEB belongs to the group of triazole fungicides that interact with the enzyme 14- $\alpha$-demethylase, which plays a role in the sterol biosynthetic pathways in eukaryotes (Bowen et al. 1997; Sun et al. 2011). TEB is applied on several crops, especially on fruits (grapes, apple, pear), vegetables, cereals (wheat, barley, oat, rye), and oilseed rape, and particularly in The Netherlands also on flower bulbs in floriculture. Moreover, TEB is one of the most frequently applied fungicides in the European Union (EC 2007).

In 2009, TEB was approved in Europe, following a peer review of the risk assessment documentation by the European Food and Safety Authority (EFSA). Although EFSA stated that the risk assessment was incomplete, TEB is 
currently classified as 'harmful if swallowed' and based on the effects observed in different species as 'suspected of damaging the unborn child' (EFSA 2014). The Joint Meeting on Pesticide Residues (JMPR) concluded that TEB is neither genotoxic nor mutagenic, and that the established acceptable daily intake (ADI) of $0.03 \mathrm{mg} / \mathrm{kg}$ body weight is appropriate. In addition, the JMPR reported no health impairments after short-term or long-term occupational exposure to TEB (WHO 2011). Nonetheless, endocrine disrupting properties in vitro and in vivo have been reported in several studies (Kjaerstad et al. 2010; Shen et al. 2017; Taxvig et al. 2008), and developmental toxicity in animal studies was reported by the U.S. Environmental Protection Agency (EPA) in 1992 (Burin and Protzel 1992).

Humans may be exposed via the consumption of fruits, vegetables, grains, and drinks (e.g., wine) that could contain residues of TEB. Residents living in rural areas or close to agricultural land may additionally be exposed via the environment, and agricultural workers via inhalation or direct skin contact during spray applications of TEB or when reentering a recently sprayed field or crop.

Aggregate exposure and potential health risks of xenobiotic substances can be assessed by use of human biological monitoring (HBM) and by applying knowledge on the toxicokinetics of the compound of interest. In HBM, chemicals and/or their metabolites can be measured in biological media, such as urine, saliva, or exhaled air. Urine is commonly used in environmental epidemiology since it reflects the absorbed dose via all routes of exposure over a specific period of time. In addition, urine can be collected easily by the participants themselves without an invasive or complex procedure (Scheepers 2015).

For the sound interpretation of HBM results, e.g., in the context of risk assessment, information on the toxicokinetics is required. Animal studies have elucidated the fate of TEB in different species, including the chemical identity of a number of urinary metabolites and their conjugates. The major metabolites reported in animals were tebuconazole-1-hydroxy (TEB-OH) and tebuconazole-carboxylic acid (TEB-COOH) after deconjugation. Mercadante et al. identified TEB-OH and TEB-COOH as the most abundant metabolites in urine after dermal exposure of vineyard workers who applied TEB (Mercadante et al. 2014). In a study of Fustinoni et al., the TEB-OH/TEB-COOH ratio was reported to be 3.5 (Fustinoni et al. 2014). Although previous studies confirmed TEB-OH and TEB-COOH as major metabolites, with TEB-OH as the most abundant, quantitative data on the toxicokinetics after controlled exposure of TEB in humans have not been published.

Therefore, we designed a human volunteer study with controlled single oral or dermal administration of TEB to elucidate the time course of excretion in urine. The objectives of this study were to determine the toxicokinetics of
TEB, and to compare the observed time courses of excretion of TEB-OH in a physiologically based toxicokinetic (PBTK) model.

\section{Materials and methods}

\section{Study design}

Participants were recruited in the area of Nijmegen, The Netherlands, by distribution of hardcopy leaflets and online announcements. Three male and three female healthy nonsmoking volunteers received a single oral or dermal dose of TEB in random order on two occasions, separated by at least 2 weeks to prevent carryover. None of the volunteers used any medication during the study period, except oral contraceptives, and occupational exposure to pesticides was not reported.

A fixed oral dose of $1.5 \mathrm{mg}$ was predefined for all participants and corresponds to the ADI for TEB of $0.03 \mathrm{mg} / \mathrm{kg}$ for a person with a body weight of $50 \mathrm{~kg}$. For oral administration, a $200 \mathrm{~mL}$ solution of $1.5 \mathrm{mg}$ of TEB in tap water was prepared. The solution was ingested within $1 \mathrm{~min}$.

For the dermal application, the participants received a fixed dose of $2.5 \mathrm{mg}$ of TEB $(100 \mu \mathrm{L}$ of a $25 \mathrm{mg} / \mathrm{mL}$ acetone solution) which was applied on a marked rectangular surface of $25 \mathrm{~cm}^{2}$ of the non-dominant forearm. The volunteer was invited to sit next to a fume hood with the arm inside. The solution was applied in the fume hood to prevent inhalation of TEB evaporating from the treated skin. Due to the high volatility of acetone, the liquid evaporated immediately resulting in a direct exposure to solid TEB. After $1 \mathrm{~h}$, the exposure was stopped by a gentle and short cleaning procedure (once horizontally, once vertically) of the skin surface with a tissue immersed in a solution of water and ethanol $(50: 50 \mathrm{v} / \mathrm{v})$. The estimated systemic uptake after topical application during the first hour was $19 \mu \mathrm{g}$ of TEB (1.2\% of the ADI) by calculation using IH-SkinPerm v1.21. SkinPerm is a model to estimate dermal absorption over time, depending on physico-chemical properties of the compound and skin surface area (AIHA 2011; Tibaldi et al. 2014). The potential uptake for the particular skin surface area and time of application was maximized until skin uptake of TEB became saturated.

Participant characteristics and oral and dermal doses expressed in $\mu$ g per kg body weight are shown in Table 1 . The volunteers were made aware of food items which could contain residues of TEB (e.g., grapes, peaches, nectarines) and were asked to refrain from consumption of these items from $48 \mathrm{~h}$ before and during the urine collection periods. Just before each administration, a pre-exposure urine sample was obtained and this time point was set to zero. Urine was sampled in separate portions at $2 \mathrm{~h}$ intervals for the 
Table 1 Participant characteristics and oral and dermal dose of TEB normalized for body weight

\begin{tabular}{|c|c|c|c|c|c|}
\hline Person code $^{\mathrm{a}}$ & Height $(\mathrm{cm})$ & Weight (kg) & Age (years) & $\begin{array}{l}\text { Oral dose }(\mu \mathrm{g} / \\
\mathrm{kg} \mathrm{bw})\end{array}$ & $\begin{array}{l}\text { Dermal } \\
\text { uptake }{ }^{b}(\mu \mathrm{g} / \\
\mathrm{kg} \mathrm{bw})\end{array}$ \\
\hline$F 1$ & 168 & 58 & 23 & 26 & 0.32 \\
\hline$F 2$ & 170 & 58 & 24 & 26 & 0.32 \\
\hline$F 3$ & 174 & 68 & 20 & 22 & 0.27 \\
\hline$F-\mathrm{Mean}^{\mathrm{c}}$ & 171 & 61 & 23 & 25 & 0.31 \\
\hline$M 4$ & 187 & 67 & 28 & 22 & 0.28 \\
\hline M5 & 185 & 75 & 23 & 20 & 0.25 \\
\hline$M 6$ & 185 & 70 & 21 & 21 & 0.27 \\
\hline$M-\mathrm{Mean}^{\mathrm{c}}$ & 186 & 71 & 24 & 21 & 0.26 \\
\hline
\end{tabular}

first $8 \mathrm{~h}$ and further without time restriction up to $48 \mathrm{~h}$ after administration. The clock time of each urine micturition was recorded by the participant on a registration form. Urine was collected in $500 \mathrm{~mL}$ polyethylene containers and samples were kept at $7{ }^{\circ} \mathrm{C}$ in a mobile cooler by the participant. All urine specimens were transported to the laboratory, where urine volume was measured and the samples were homogenized, separated in $50 \mathrm{~mL}$ aliquots, and subsequently stored at $-20{ }^{\circ} \mathrm{C}$

\section{Quantitative determination of TEB-OH}

\section{Chemicals}

Hydroxy-tebuconazole (TEB-OH; purity $>98 \%$ ) and the internal standard (IS) D6-hydroxy-tebuconazole (D6-TEB$\mathrm{OH}$; purity $>98 \%$ ) were obtained from Alsachim (Illkirch Graffenstaden, France). HPLC-grade methanol (99.9\%) was purchased from VWR Chemicals (Fontenay-sous-Bais, France) and UHPLC-grade acetonitrile (99.9\%) from Boom (Meppel, The Netherlands). Formic acid (98\%) and acetic acid $(100 \%)$ were obtained from Merck (Darmstadt, Germany), while $\beta$-Glucuronidase/arylsulfatase aqueous solution from Helix pomatia was purchased from Roche Diagnostics (Mannheim, Germany). Purified water was obtained using a Millipore Milli-Q Advantage A10 system (Milford, MA, USA).

\section{Preparation of standards}

Stock solutions of TEB-OH and the internal standard (D6-TEB-OH) were prepared in methanol at concentrations of $2 \mathrm{mg} / \mathrm{mL}$. Working solutions of $1000 \mathrm{ng} / \mathrm{mL}$ and $100 \mathrm{ng} /$ $\mathrm{mL}$ were prepared in $95 \%$ of water and $5 \%$ of methanol $(\% \mathrm{v} / \mathrm{v})$. All standards were stored at $-20{ }^{\circ} \mathrm{C}$ in the dark. A calibration curve of TEB-OH, ranging from 0.05 to $100 \mathrm{ng} /$
$\mathrm{mL}$, including a blank urine, was prepared in a mixture of urine samples from unexposed humans, by adding suitable amounts of the working solutions to aliquots of the urine. Each calibration standard was prepared identical to the samples, including addition of the internal standard.

\section{Sample preparation}

All specimens were thawed at room temperature, prior to sample preparation. An aliquot of $5 \mathrm{~mL}$ of urine was transferred into an Erlenmeyer and $50 \mu \mathrm{L}$ of the internal standard working solution was added, resulting in a $1 \mathrm{ng} / \mathrm{mL}$ concentration of D6-TEB-OH in urine. For deconjugation, $5 \mu \mathrm{L}$ of Helix pomatia $\beta$-glucuronidase/arylsulfatase was dissolved per $2.5 \mathrm{~mL}$ acetic acid solution in aqua pure $(0.25 \mathrm{M}, \mathrm{pH}$ 4.75), and $2.5 \mathrm{~mL}$ of this mixture was added to each sample. The samples were incubated overnight for at least $16 \mathrm{~h}$ at $37{ }^{\circ} \mathrm{C}$ under gentle agitation, after which a subzero-temperature liquid-liquid extraction was performed as previously described (Yoshida and Akane 1999???). Briefly, the samples were first centrifuged at $1800 \mathrm{RCF}$, and $1 \mathrm{~mL}$ of the supernatant was transferred to a test tube. After adding an aliquot of $3 \mathrm{~mL}$ of acetonitrile, the sample was mixed and placed at $-20{ }^{\circ} \mathrm{C}$ for $20 \mathrm{~min}$ to separate the organic layer from the aqueous layer. One milliliter of the organic layer was transferred to a vial for subsequent LC-MS/MS analysis.

\section{LC-MS/MS analysis}

For the quantification of TEB-OH, an aliquot of $2.5 \mu \mathrm{L}$ of each sample was analyzed on a Waters Acquity H-Class LC system equipped with a quaternary pump (Waters, Milford, MA, USA). The LC was coupled to a Waters TQ-S micro tandem MS (Waters, Milford, MA, USA) using electro spray ionization (ESI). The chromatographic separation was 
performed on a Waters BEH C18 column, $50 \mathrm{~mm} \times 2.1 \mathrm{~mm}$, $1,7 \mu \mathrm{m}$ (Waters, Ireland) at $60{ }^{\circ} \mathrm{C}$ with a flow rate of $400 \mu \mathrm{L} /$ min. Gradient elution consisted of solvent A (5\% of methanol and $0.1 \%$ of formic acid in aqua pure) and solvent $\mathrm{B}$ (100\% of methanol) and was performed as follows: $0.0 \mathrm{~min}$, $20 \% \mathrm{~B} ; 1.0 \mathrm{~min}, 100 \% \mathrm{~B} ; 3.5 \mathrm{~min}, 100 \% \mathrm{~B} ; 4.0 \mathrm{~min}, 20 \%$ B; $4.5 \mathrm{~min}, 20 \% \mathrm{~B}$. Positive ESI $(+2.0 \mathrm{kV})$ was applied at $600{ }^{\circ} \mathrm{C}$ under a nitrogen flow of $1100 \mathrm{~L} / \mathrm{h}$ and a cone nitrogen flow of $50 \mathrm{~L} / \mathrm{h}$. The MS was operated in multiple reaction monitoring (MRM) mode. The mass transitions selected for quantification and qualification of TEB-OH were $325.02>69.96$, with a collision energy (CE) of $20 \mathrm{eV}$, and $325.02>124.97(\mathrm{CE} 40 \mathrm{eV})$, respectively. The mass transition selected for quantification of D6-TEB-OH was $331.02>69.69$ (CE $20 \mathrm{eV})$.

\section{Calculations}

For each individual, the cumulative amount of TEB-OH excreted in urine over $48 \mathrm{~h}$ was calculated as the molar fraction of the administered dose. The ratio between the dose (in nmol) and the amount recovered as metabolite (in nmol) in urine was calculated and defined as the conversion factor.

To determine the excretion of TEB-OH in urine over time, the excretion rate (ER) in $\mathrm{nmol} / \mathrm{h}$ for each collection interval was calculated as follows: $\mathrm{ER}=$ absolute amount in sample (nmol)/midtime collection interval (h). The absolute amount of TEB-OH was calculated by multiplying the urine void volume $(\mathrm{mL})$ with the obtained concentration in $(\mathrm{ng} /$ $\mathrm{mL}$ ). The midtime was defined as:

$t_{\text {mid }}=t_{i-1}+\left(t_{i}-t_{i-1}\right) / 2$.

The individual excretion curves were created by plotting the ER versus the midtime of the corresponding collection interval. From each ER-time profile, the elimination rate constant $\left(k_{\mathrm{e}}\right)$, the urinary excretion half-life $\left(t_{1 / 2}\right)$, and the area under the renal excretion curve (AUR) were calculated. The $k_{\mathrm{e}}$ was determined from the slope of the elimination phase of the ER-time profile, and the $t_{1 / 2}$ was then calculated as follows:

$t_{1 / 2}=\ln 2 / k_{\mathrm{e}}$.

The AUR was calculated by taking the sum of the absolute amount in each urine sample.

\section{PBTK modeling}

The PBTK modeling was performed using Berkeley Madonna software package v8.3.18. The time courses of excretion obtained from the volunteers were compared to a simulation of TEB-OH excretion in urine over time by use of an existing PBTK model that was specifically developed for TEB (Jónsdóttir et al. 2016). This model was extended by connecting it with a parallel model describing the distribution of TEB-OH. Furthermore, hepatic clearance of TEB$\mathrm{OH}$ was included, and the kidney and gut compartments were added. The stratum corneum was included to be able to simulate the delayed uptake from the skin (Fig. 1). The two enantiomers of TEB were not modeled separately as a racemic mixture of TEB was administered to the volunteers. Compound-specific parameters, physiological parameters for humans (i.e., cardiac output, tissue volumes, organ blood flows), and parameters for metabolism were adopted under the same assumptions as in the original model (Jónsdóttir et al. 2016). For the compound-specific parameters of the metabolite, we assumed that the partition coefficients were decreased with the ratio of the $\log P_{\mathrm{o} / \mathrm{w}}$ of the metabolite over that of the parent compound. Dermal absorption constants were fitted to mimic the observed data from the volunteers. To calculate the concentration in urine over time, the concentration of TEB-OH in the kidney compartment was multiplied with the glomerular filtration rate. The used syntax can be found in supplemental material 1 .

\section{Results and discussion}

This study provides new insights into the toxicokinetics of TEB following controlled oral and dermal administration as determined by the excreted fractions and time courses of its main metabolite TEB-OH in urine, the accompanying toxicokinetic parameters, and a comparison with a PBTK model for TEB.

After quantification of TEB-OH in each single urine sample, the recoveries and conversion factors were calculated for each individual. Following oral administration, the mean recovery $( \pm \mathrm{SD})$ of TEB-OH in urine during $48 \mathrm{~h}$ was $38 \% \pm 16 \%$ and the mean conversion factor was $3.0 \pm 1.0$ (Table 2). Different animal studies reported a total urinary excretion of all metabolites between 16 and 35\% (EFSA 2014; WHO 2011). Thus, the average fraction of the dose in humans excreted as urinary metabolite in our volunteer study was higher compared to that in animals, as only TEB$\mathrm{OH}$ was already recovered for $38 \%$ in urine after $48 \mathrm{~h}$.

After dermal exposure to $2.5 \mathrm{mg}$ of TEB, the mean recovery of TEB-OH in urine was $1.0 \% \pm 0.5 \%$ and the conversion factor was $116 \pm 42$ (Table 3). No studies were found that investigated the amount of urinary excretion after dermal exposure in animals. Two studies, described in the EC draft assessment report, found that approximately $55 \%$ of TEB was absorbed through the skin in rats and $13 \%$ in rhesus monkeys (EC 2007). However, dermal absorption is dependent on the concentration of the substance, the formulation of the applied solution, and the skin surface area, but information on the amounts applied, exposure durations, and application methods was not reported. Furthermore, it is 


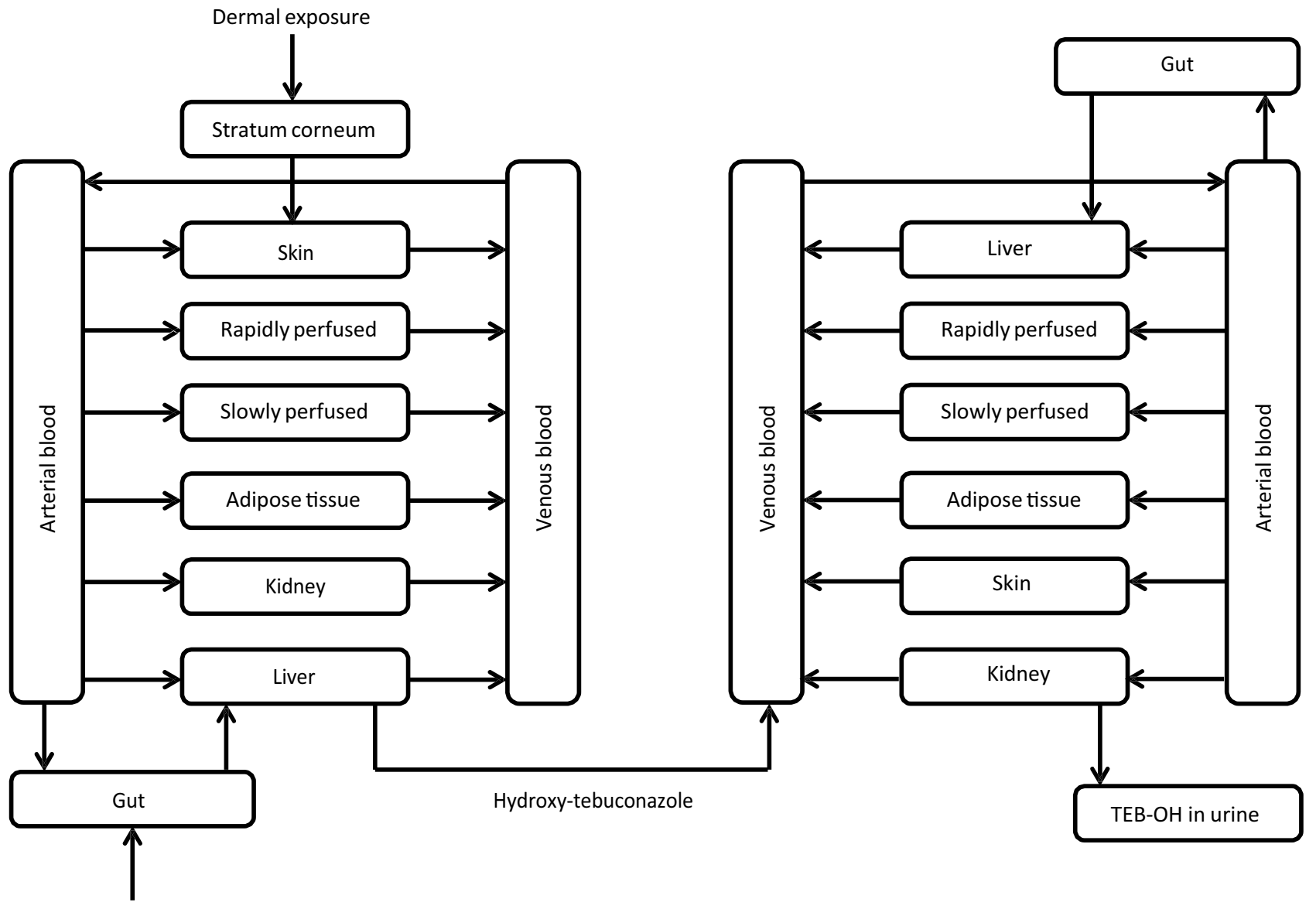

Oral exposure

Fig. 1 Schematic representation of the adapted PBTK model for tebuconazole and hydroxy-tebuconazole. It describes two routes of administration (oral and dermal), distribution in the compartments, metabolism in the liver, distribution of the metabolite hydroxy-tebuconazole in a parallel model and renal excretion of the metabolite into urine
Table 2 Toxicokinetic parameters of TEB-OH derived from individual time courses of excretion following oral ingestion of $1.5 \mathrm{mg}$ of tebuconazole

\begin{tabular}{|c|c|c|c|c|c|c|c|}
\hline \multirow[t]{2}{*}{ Oral $(n=6)$} & \multicolumn{3}{|c|}{ Female } & \multicolumn{3}{|l|}{ Male } & \multirow[t]{2}{*}{ Mean \pm SD } \\
\hline & $F 1$ & $F 2$ & $F 3$ & $M 1$ & $M 2$ & M3 & \\
\hline Excreted fraction of dose $(48 \mathrm{~h})$ & 0.37 & 0.28 & 0.27 & 0.66 & 0.24 & 0.47 & $0.38 \pm 0.16$ \\
\hline Conversion factor & 2.7 & 3.6 & 3.6 & 1.5 & 4.2 & 2.1 & $3.0 \pm 1.0$ \\
\hline$T_{\max }(\mathrm{h})$ based on $\mu \mathrm{mol} / \mathrm{L}$ & 3.0 & 3.1 & 7.4 & 0.9 & 9.1 & 1.0 & $4.1 \pm 3.4$ \\
\hline$T_{\max }(\mathrm{h})$ based on excretion rate & 1.5 & 1.1 & 1.0 & 0.9 & 2.7 & 1.0 & $1.4 \pm 0.7$ \\
\hline$C_{\max }(\mu \mathrm{mol} / \mathrm{l})$ & 2.1 & 1.5 & 0.8 & 2.5 & 1.5 & 5.8 & $2.4 \pm 1.8$ \\
\hline$K_{\mathrm{e}}\left(\mathrm{h}^{-1}\right)$ & 0.09 & 0.12 & 0.08 & 0.08 & 0.08 & 0.09 & $0.09 \pm 0.01$ \\
\hline$t_{1 / 2}(\mathrm{~h})$ & 7.6 & 6.0 & 8.5 & 8.7 & 8.4 & 7.4 & $7.8 \pm 1.0$ \\
\hline AUR $(\mu \mathrm{g})$ & 575 & 457 & 352 & 694 & 360 & 661 & $520 \pm 150$ \\
\hline
\end{tabular}

known that the rat skin is ten times more permeable than the human skin (van Ravenzwaay and Leibold 2004). After application of TEB, Fustinoni et al. reported a total amount of metabolites excreted in the first $24 \mathrm{~h}$ of approximately $17 \%$, but the potential total body exposure was up to $21 \mathrm{mg}$, while the occupational exposure duration was considerably longer than $1 \mathrm{~h}$ (Fustinoni et al. 2014). Both the relatively small exposed skin surface area $\left(25 \mathrm{~cm}^{2}\right)$ and the short exposure time restriction in our study could have led to a lower uptake percentage compared to other studies. Nonetheless, the modeled dermal uptake after $1 \mathrm{~h}(19 \mu \mathrm{g}, 59 \mathrm{nmol})$ and the amount of TEB-OH recovered in urine $(26 \mu \mathrm{g}, 80 \mathrm{nmol})$ 
Table 3 Toxicokinetic parameters derived from individual time courses of excretion following dermal administration of $2.5 \mathrm{mg}$ during $1 \mathrm{~h}$ of tebuconazole

\begin{tabular}{|c|c|c|c|c|c|c|c|}
\hline \multirow[t]{2}{*}{ Dermal $(n=6)$} & \multicolumn{3}{|l|}{ Female } & \multicolumn{3}{|l|}{ Male } & \multirow[t]{2}{*}{ Mean \pm SD } \\
\hline & $F 1$ & $F 2$ & $F 3$ & $M 1$ & $M 2$ & $M 3$ & \\
\hline Excreted fraction of dose ( $48 \mathrm{~h})$ & 0.010 & 0.008 & 0.010 & 0.008 & 0.018 & 0.006 & $0.010 \pm 0.005$ \\
\hline Conversion factor & 103 & 130 & 104 & 125 & 54 & 181 & $116 \pm 42$ \\
\hline$T_{\max }(\mathrm{h})$ based on $\mu \mathrm{mol} / \mathrm{L}$ & 18.1 & 18.8 & 19.4 & 18.9 & 18.6 & 25.9 & $19.9 \pm 2.9$ \\
\hline$T_{\max }$ (h) based on excretion rate & 23.1 & 11.1 & 25.8 & 26.1 & 24.9 & 13.4 & $20.8 \pm 6.7$ \\
\hline$C_{\max }(\mu \mathrm{mol} / \mathrm{l})$ & 0.14 & 0.04 & 0.04 & 0.07 & 0.10 & 0.02 & $0.07 \pm 0.04$ \\
\hline$K_{\mathrm{e}}\left(\mathrm{h}^{-1}\right)$ & 0.05 & 0.03 & 0.04 & 0.05 & 0.05 & 0.04 & $0.05 \pm 0.01$ \\
\hline$t_{1 / 2}(\mathrm{~h})$ & 14.4 & 22.2 & 15.6 & 13.4 & 13.3 & 15.8 & $15.8 \pm 3.3$ \\
\hline AUR $(\mu g)$ & 25 & 20 & 27 & 21 & 48 & 15 & $26 \pm 12$ \\
\hline
\end{tabular}

were in the same order of magnitude. When extending the skin uptake period to $24 \mathrm{~h}$ in the SkinPerm model, the absorbed fraction becomes $18 \%$, which is comparable to the findings in the study of Fustinoni et al. (2014). Moreover, we do not expect that a large skin surface area of residents will get in direct contact with the substance. For ethical and practical reasons, we decided to restrict the exposure duration to $1 \mathrm{~h}$, and for comparison with the oral exposure scenario, we collected urine up to $48 \mathrm{~h}$ after exposure in this volunteer study. We do not anticipate that acetone, as a vehicle, affected the dermal absorption rate or total dermal absorption, because this small volume $(100 \mu \mathrm{L})$ is immediately evaporated from the skin surface.

The time courses of the excretion rate of TEB-OH in urine following oral and dermal administration of TEB are shown in Figs. 2 and 3. The curves are plotted on a semilogarithmic scale and each line represents the excretion rate in $\mathrm{nmol} / \mathrm{h}$ of one volunteer. Additionally, the creatinineadjusted urine concentrations in $\mu \mathrm{g} / \mathrm{g}$ creatinine are shown to correct for dilution effects. On the $x$-axis, the midtime of the urine collection interval is shown. In the pre-exposure samples, the concentrations of TEB-OH were below the limit of detection or very low (maximum of $5 \mathrm{nmol} / \mathrm{L}$ ). All of the excretion patterns among the volunteers were in good agreement with each other. Creatinine-corrected metabolite concentrations and excretion rates following oral exposure decreased rapidly within a few hours after administration. It is shown in Fig. 2 that the excretion after oral administration was rapid and nearly complete within $48 \mathrm{~h}$ which was also described in the EFSA and WHO reports (EFSA 2014; WHO 2011). Therefore, the conclusion from rat studies that there is limited or no potential for accumulation in the body seems also valid for human.

Following dermal application, a progressive increase in urinary metabolites was observed up to approximately $20 \mathrm{~h}$; the elimination phase was considerably slower compared to oral administration (Fig. 3) but elimination was not completed after $48 \mathrm{~h}$. This can be explained by the relatively slow process of skin absorption through the stratum corneum as a reservoir, which allows for continued uptake into
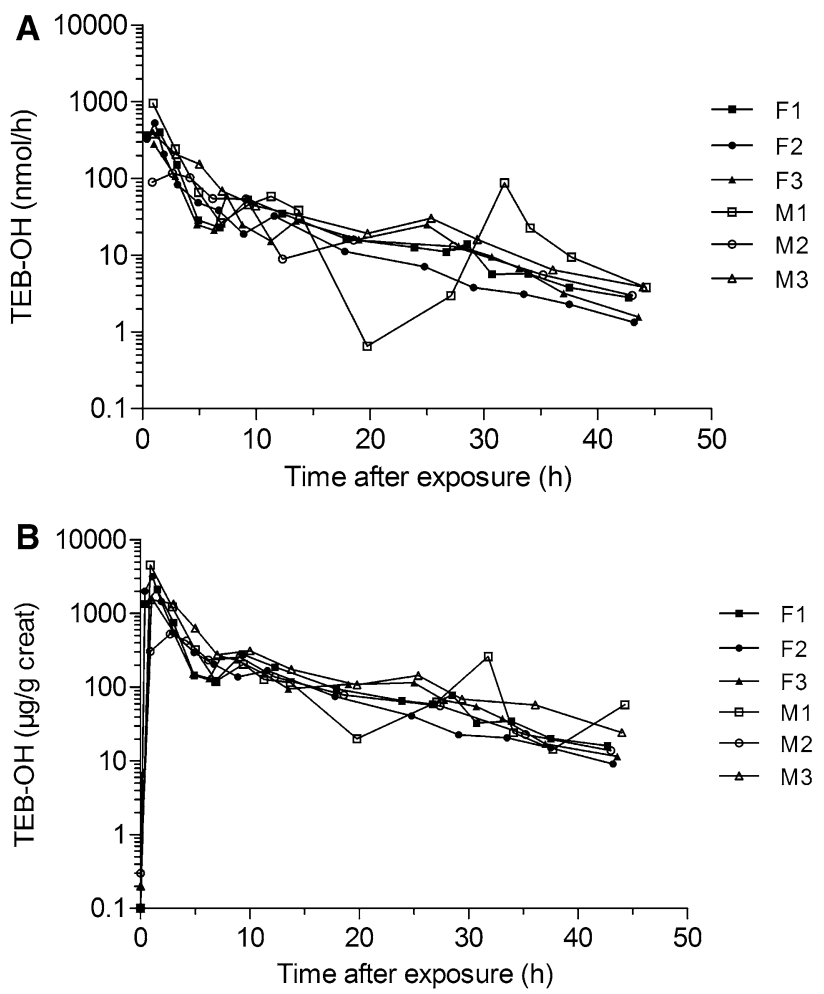

Fig. 2 Time course of the urinary excretion of TEB-OH after oral administration in six human volunteers on a semi-logarithmic scale: a represents the excretion rate in $\mathrm{nmol} / \mathrm{h}$, b represents the creatininecorrected TEB-OH concentrations in $\mu \mathrm{g} / \mathrm{g}$ creatinine

the body for relatively long periods of time even when the external exposure was stopped (Rom and Markowitz 2007). After reaching the maximum concentration in urine, the excretion followed first-order elimination kinetics in both exposure scenarios. No significant difference in the toxicokinetics was observed between males and females, which was also concluded by the JMPR (WHO 2011). A longer urine collection time up to, for example, $72 \mathrm{~h}$ or $96 \mathrm{~h}$ after dermal exposure would have allowed to measure the last part of the time course of excretion of TEB-OH. As information on the dermal toxicokinetics was not described in animal studies 

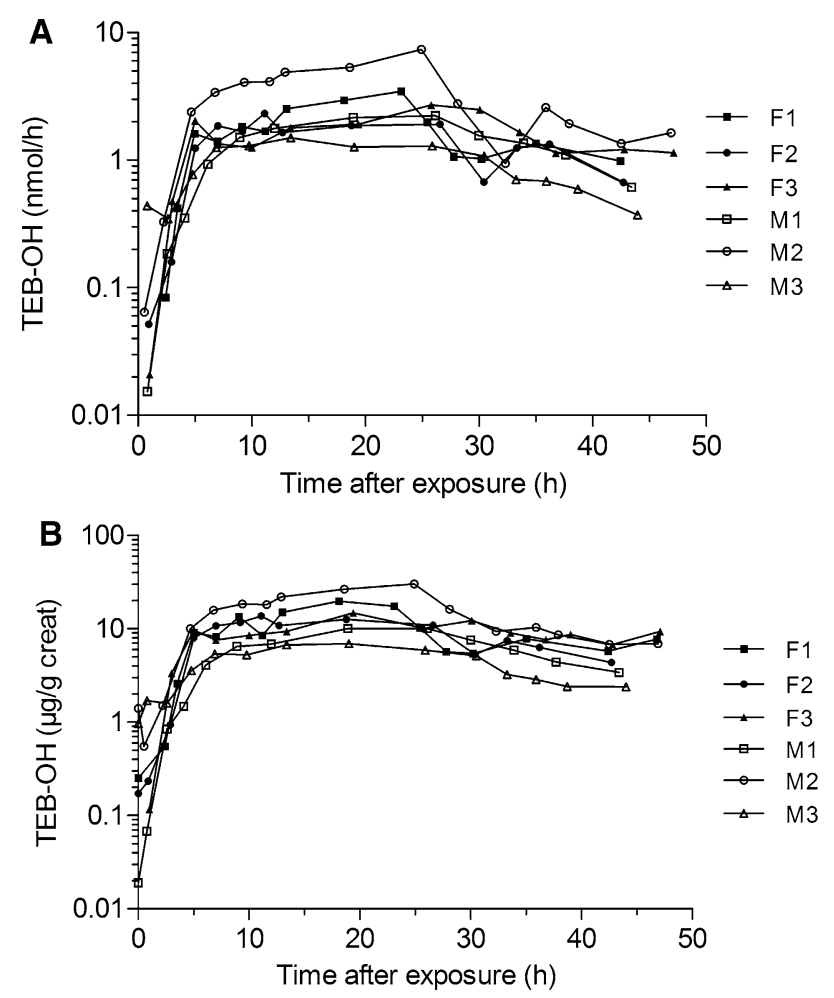

Fig. 3 Time course of the urinary excretion of TEB-OH after dermal administration in six human volunteers on a semi-logarithmic scale: a represents the excretion rate in $\mathrm{nmol} / \mathrm{h}$, b represents the creatininecorrected TEB-OH concentrations in $\mu \mathrm{g} / \mathrm{g}$ creatinine

before, we decided to apply the same sampling strategy as for oral exposure. After dermal exposure, log-linear extrapolation of the urinary excretion rate-time curve resulted in an estimated total excreted dose (AUR) that was approximately $20 \%$ higher than the recovery at the last collection time. The excretion-time course of participant M1 showed an aberrant pattern. This could probably be explained by incorrect registration of urine collection times or urine volumes by the volunteer. After correction for creatinine, the pattern is still not in line with that of the others.

Table 2 presents the elimination characteristics of TEB$\mathrm{OH}$ after oral administration, calculated from the excretion profiles in urine. The time point of maximum TEB-OH concentration and excretion rate ranged from 0.9 to $9.1 \mathrm{~h}$ and from 0.9 to $2.7 \mathrm{~h}$, respectively, and maximum concentrations of TEB-OH ranged from 0.8 to $5.8 \mu \mathrm{mol} / \mathrm{L}$. The mean elimination rate constant was $0.09 \mathrm{~h}^{-1}$, with a corresponding mean half-life of $7.8 \mathrm{~h}$. The calculated AUR over a $48 \mathrm{~h}$ period was on average $520 \mu \mathrm{g}$ of TEB-OH, which is a measure of the total amount recovered in urine. These findings were in line with several rat studies, which concluded that following oral administration TEB is rapidly absorbed, distributed, metabolized, and excreted, almost completely within 72 h. In Sprague-Dawley rats, maximum plasma

concentrations were reached between 0.3 and $1.7 \mathrm{~h}$. This indicates a rapid distribution in the body and limited or no potential for accumulation in different tissues. An in vivo study in rabbits suggested a plasma half-life of $1.7 \mathrm{~h}$ after i.v. administration (Zhu et al. 2007).

In Table 3, the elimination characteristics of TEB-OH following dermal administration are presented. The time point of maximum TEB-OH concentration and excretion rate, ranged from 18.1 to $25.9 \mathrm{~h}$ and from 11.1 to $16.1 \mathrm{~h}$, respectively, and maximum urine concentrations ranged from 0.04 to $0.14 \mu \mathrm{mol} / \mathrm{L}$. The mean elimination rate constant was $0.05 \mathrm{~h}^{-1}$, which corresponds to a half-life of $15.8 \mathrm{~h}$. The mean AUR over the first $48 \mathrm{~h}$ post-administration was $26 \mu \mathrm{g}$ of TEB-OH. Although little information is available on TEB excretion or metabolism after dermal exposure, Fustinoni et al. stated that the half-life of TEB-OH should be longer than $16 \mathrm{~h}$, roughly corresponding to the time between two work shifts (Fustinoni et al. 2014). These occupational exposure data are in line with our findings after single dermal administration.

In Fig. 4 the time courses of urinary excretion of TEB-OH resulting from the volunteers and the simulated excretion patterns using the adjusted PBTK model are compared for both oral and dermal exposure. The simulated time courses of excretion rates are within the range of the observed data in the volunteers. The modeled oral $T_{\max }$ based on the excretion rate was $0.7 \mathrm{~h}$ versus $1.4 \mathrm{~h}$ in volunteers. The process of gastric emptying and uptake through the gut probably results in somewhat lower peak times. The blood flow-limited model assumes rapid transmembrane movement and tissue distribution of TEB, as the capillary membrane does not provide any resistance to permeation, which explains the underestimated peak in the urinary excretion rate (Shargel et al. 2012). The modeled $T_{\max }$ for dermal absorption of $16.3 \mathrm{~h}$ was comparable to $20.8 \mathrm{~h}$ observed in the human experiment. The simulated $k_{\mathrm{e}}, t_{1 / 2}$, and AUR following oral administration were $0.07 \mathrm{~h}^{-1}, 10.2 \mathrm{~h}$, and $479 \mu \mathrm{g}$ versus $0.09 \mathrm{~h}^{-1}, 7.8 \mathrm{~h}$, and $520 \mu \mathrm{g}$ in the volunteers, respectively. The model slightly overestimated the oral half-life by a factor of 1.3 , but the total recovery was in the same range. Regarding dermal exposure, the modeled versus measured $k_{\mathrm{e}}, t_{1 / 2}$, and AUR were $0.04 \mathrm{~h}^{-1}, 18.7 \mathrm{~h}$, and $26 \mu \mathrm{g}$ versus $0.05 \mathrm{~h}^{-1}, 15.8 \mathrm{~h}$, and $26 \mu \mathrm{g}$, respectively, resulting in a somewhat longer half-life by a factor of 1.2, and a similar area under the curve indicating the total amount excreted.

Overall, this study shows that the modeled time courses of urinary excretion rates were in line with the observed data. The model might be further improved by adding partition coefficients and intrinsic clearances of the metabolite as well as dermal absorption constants of the parent compound. In the current model, the tissue plasma partition coefficients of the metabolite were calculated based on the ratio between the estimated $\log P_{\mathrm{o} / \mathrm{w}}$ values of TEB-OH and 

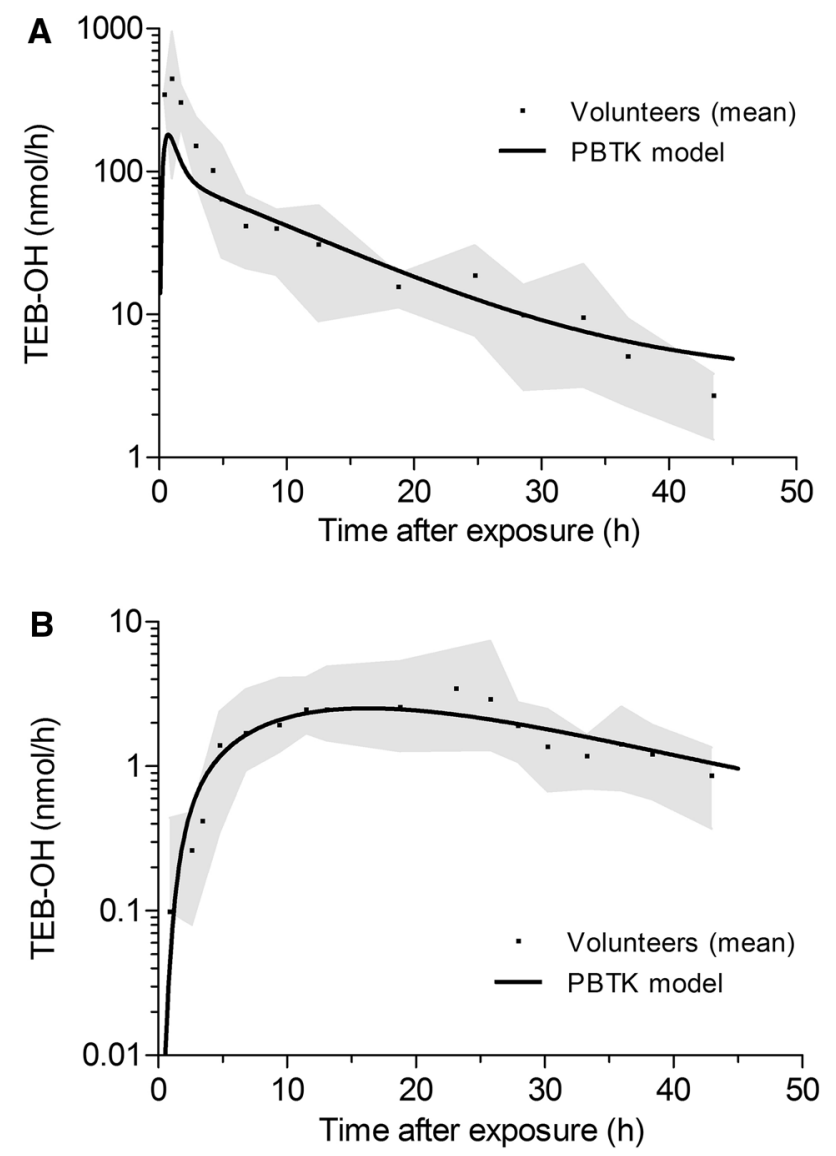

Fig. 4 Comparison of the mean time course of the urinary excretion rate of TEB-OH after oral (a) and dermal (b) administration in six human volunteers (dots) versus the simulated excretion rate using the adjusted PBTK model (line). The grey area represents the range of the observed values in the volunteers; outliers were excluded in these figures

TEB. Furthermore, we assumed the same fraction unbound in plasma for TEB-OH as for TEB. As the skin serves as a depot from which a substance can be slowly absorbed into the systemic circulation, the mathematical description of dermal absorption might be improved by implementing a dermal absorption model, rather than fitting the absorption constants.

The major strength of this study is that the oral and dermal toxicokinetics of TEB were studied under controlled conditions, in which all other potentially disturbing sources of exposure (occupational, food) were excluded. Furthermore, the previously described PBPK model for TEB was improved by use of the human data obtained. The major weakness of this study is that the time period of urine collection after administration of the dose was relatively short. Especially in the dermal exposure scenario, the elimination was not fully completed after $48 \mathrm{~h}$, but the extrapolated total recovery did not increase more than $20 \%$ beyond the last time point, which is generally considered as acceptable in these types of studies. For future volunteer studies with other fungicides, we advise to collect urine for a longer period of time and, if available, in accordance with the elimination kinetics obtained from animal studies. Another limitation is that we did not study the second metabolite of TEB, namely TEB-COOH, consequently the ratio between these two metabolites was not addressed.

\section{Conclusion}

In this study, the first human in vivo data regarding the metabolism and toxicokinetics after controlled oral and dermal administration of TEB were provided. TEB-OH was quantified and detected in each urine void collected up to $48 \mathrm{~h}$ after administration. On an average, $38 \%$ and $1.0 \%$ of the dose administered was recovered in urine during $48 \mathrm{~h}$ as TEB-OH after oral and dermal exposure, respectively. However, the elimination was not fully completed in the $48 \mathrm{~h}$ post-exposure observation period, especially after dermal administration. Peak excretion rates were reached after $1.4 \mathrm{~h}$ and $20.8 \mathrm{~h}$, while the elimination half-lives of TEB-OH in urine were $7.8 \mathrm{~h}$ and $15.8 \mathrm{~h}$ after oral and dermal administration, respectively. The time courses of excretion were compared to an extended PBTK model and the simulations were in good agreement with the human volunteer data. This study provides important data to understand the metabolism and toxicokinetics of TEB, which can be implemented in human biological monitoring or risk assessment.

Acknowledgements All volunteers are gratefully acknowledged for their willingness to participate in this study. We would also like to thank Mrs. Esther Beckers who provided invaluable support to participant recruitment and testing.

Funding This work was partly supported by the Dutch National Institute for Public Health and the Environment (RIVM).

\section{Compliance with ethical standards}

Conflict of interest The authors declare that they have no potential conflict of interest.

Ethical approval The study protocol with one amendment was approved by the Regional Committee on Research Involving Human Subjects Arnhem-Nijmegen (No. 2016-2267) in accordance with the 1964 Helsinki declaration and its later amendments. Written informed consent was obtained from all individual participants included in the study.

Open Access This article is distributed under the terms of the Creative Commons Attribution 4.0 International License (http://creativeco mmons.org/licenses/by/4.0/), which permits unrestricted use, distribution, and reproduction in any medium, provided you give appropriate credit to the original author(s) and the source, provide a link to the Creative Commons license, and indicate if changes were made. 


\section{References}

American Industrial Hygiene Association (AIHA) (2011) Exposure Assessment Strategies Committee (EASC), IH SkinPerm, v1.21. https://www.aiha.org/get-involved/VolunteerGroups/Pages/Expos ure-Assessment-Strategies-Committee.aspx

Bowen KL, Hagan AK, Weeks JR (1997) Number of tebuconazole applications for maximizing disease control and yield of peanut in growers' fields in Alabama. Plant Dis 81(8):927-931. https:// doi.org/10.1094/Pdis.1997.81.8.927

Burin GJ, Protzel A (1992) Developmental and reproductive toxicity peer review of tebuconazole. United States Environmental Protection Agency EPA, Washington, D.C.

Child RD, Evans DE, Allen J, Arnold GM (1993) Growth-responses in oilseed rape (Brassica-Napus L) to combined applications of the triazole chemicals triapenthenol and tebuconazole and interactions with gibberellin. Plant Growth Regul 13(2):203-212. https ://doi.org/10.1007/Bf00024263

EC (2007) Draft assessment report tebuconazole, vol 3. European Commission, Brussels, Belgium

EFSA (2014) Conclusion on the peer review of the pesticide risk assessment of the active substance tebuconazole. EFSA J 12(1):3485. https://doi.org/10.2903/j.efsa.2014.3485 (98)

Fustinoni S, Mercadante R, Polledri E et al (2014) Biological monitoring of exposure to tebuconazole in winegrowers. J Expo Sci Environ Epidemiol 24(6):643-649. https://doi.org/10.1038/jes.2014.14

Jónsdóttir SO, Reffstrup TK, Petersen A, Nielsen E (2016) Physicologically based toxicokinetic models of tebuconazole and application in human risk assessment. Chem Res Toxicol 29(5):715-734. https://doi.org/10.1021/acs.chemrestox.5b00341

Kjaerstad MB, Taxvig C, Nellemann C, Vinggaard AM, Andersen HR (2010) Endocrine disrupting effects in vitro of conazole antifungals used as pesticides and pharmaceuticals. Reprod Toxicol 30(4):573-582. https://doi.org/10.1016/j.reprotox.2010.07.009

Larena I, Torres R, De Cal A et al (2005) Biological control of postharvest brown rot (Monilinia spp.) of peaches by field applications of Epicoccum nigrum. Biol Control 32(2):305-310. https://doi. org/10.1016/j.biocontrol.2004.10.010

Mercadante R, Polledri E, Scurati S, Moretto A, Fustinoni S (2014) Identification and quantification of metabolites of the fungicide tebuconazole in human urine. Chem Res Toxicol 27(11):19431949. https://doi.org/10.1021/tx500291t

Mohapatra S, Ahuja AK, Deepa M, Jagadish GK, Prakash GS, Kumar S (2010) Behaviour of trifloxystrobin and tebuconazole on grapes under semi-arid tropical climatic conditions. Pest Manag Sci 66(8):910-915. https://doi.org/10.1002/ps.1961

Rademacher W (2000) GROWTH RETARDANTS: effects on Gibberellin Biosynthesis and Other Metabolic Pathways. Annu Rev Plant Physiol Plant Mol Biol 51:501-531. https://doi.org/10.1146/ annurev.arplant.51.1.501

Rom WN, Markowitz S (2007) Environmental and occupational medicine, 4th edn. Wolters Kluwer/Lippincott Williams \& Wilkins, Philadelphia
Scheepers PTJ (2015) Human Biological Monitoring and Public Health. In: Armon RH, Hanninen O (eds) Environmental indicators. Springer Science + Business Media, Berlin

Shargel L, Wu-Pong S, Yu ABC (2012) Chapter 22. Physiologic pharmacokinetic models, mean residence time, and statistical moment theory applied biopharmaceutics and pharmacokinetics, 6th edn. The McGraw-Hill Companies, New York

Shen X, Chen F, Chen L, Su Y, Huang P, Ge RS (2017) Effects of fungicides on rat's neurosteroid synthetic enzymes. Biomed Res Int 2017:5829756. https://doi.org/10.1155/2017/5829756

Sun XP, Wang JY, Feng D, Ma ZH, Li HY (2011) PdCYP51B, a new putative sterol 14 alpha-demethylase gene of Penicillium digitatum involved in resistance to imazalil and other fungicides inhibiting ergosterol synthesis. Appl Microbiol Biot 91(4):11071119. https://doi.org/10.1007/s00253-011-3355-7

Taxvig C, Vinggaard AM, Hass U, Axelstad M, Metzdorff S, Nellemann C (2008) Endocrine-disrupting properties in vivo of widely used azole fungicides. Int J Androl 31(2):170-177. https://doi.org /10.1111/j.1365-2605.2007.00838.x

Tibaldi R, ten Berge W, Drolet D (2014) Dermal absorption of chemicals: estimation by IH SkinPerm. J Occup Environ Hyg 11(1):19_ 31. https://doi.org/10.1080/15459624.2013.831983

van Ravenzwaay B, Leibold E (2004) A comparison between in vitro rat and human and in vivo rat skin absorption studies. Hum Exp Toxicol 23(9):421-430. https://doi.org/10.1191/0960327104ht471 oa

World Health Organization (WHO) (2011) Report of the Joint Meeting of the FAO Panel of experts on pesticide residues in food and the environment and the WHO core assessment group on pesticide residues. Food and Agricluture organization of the United Nations (FAO), Rome, Italy, 21-30 September 2010, ISBN 978-92-5-106735-2

Yoshida M, Akane A (1999) Subzero-temperature liquid-liquid extraction of benzodiazepines for high performance liquid chromatography. Anal Chem 71(9):1918-1921. https://doi.org/10.1021/ac981 $276 \mathrm{~g}$

Zhang DP, Spadaro D, Garibaldi A, Gullino ML (2010) Selection and evaluation of new antagonists for their efficacy against postharvest brown rot of peaches. Postharvest Biol Tec 55(3):174-181. https ://doi.org/10.1016/j.postharvbio.2009.09.007

Zhu W, Qiu J, Dang Z et al (2007) Stereoselective degradation kinetics of tebuconazole in rabbits. Chirality 19(2):141-147. https://doi. org/10.1002/chir.20340

Publisher's Note Springer Nature remains neutral with regard to jurisdictional claims in published maps and institutional affiliations. 